Research Article

\title{
Locomotive Schedule Optimization for Da-qin Heavy Haul Railway
}

\author{
Ruiye Su, Leishan Zhou, and Jinjin Tang \\ School of Traffic and Transportation, Beijing Jiaotong University, Beijing 100044, China \\ Correspondence should be addressed to Jinjin Tang; jjtang@bjtu.edu.cn
}

Received 18 September 2015; Accepted 6 December 2015

Academic Editor: Gisella Tomasini

Copyright (C) 2015 Ruiye Su et al. This is an open access article distributed under the Creative Commons Attribution License, which permits unrestricted use, distribution, and reproduction in any medium, provided the original work is properly cited.

\begin{abstract}
The main difference between locomotive schedule of heavy haul railways and that of regular rail transportation is the number of locomotives utilized for one train. One heavy-loaded train usually has more than one locomotive, but a regular train only has one. This paper develops an optimization model for the multilocomotive scheduling problem (MLSP) through analyzing the current locomotive schedule of $\mathrm{Da}$-qin Railway. The objective function of our paper is to minimize the total number of utilized locomotives. The MLSP is nondeterministic polynomial (NP) hard. Therefore, we convert the multilocomotive traction problem into a singlelocomotive traction problem. Then, the single-locomotive traction problem (SLTP) can be converted into an assignment problem. The Hungarian algorithm is applied to solve the model and obtain the optimal locomotive schedule. We use the variance of detention time of locomotives at stations to evaluate the stability of locomotive schedule. In order to evaluate the effectiveness of the proposed optimization model, case studies for $20 \mathrm{kt}$ and $30 \mathrm{kt}$ heavy-loaded combined trains on Da-qin Railway are both conducted. Compared to the current schedules, the optimal schedules from the proposed models can save 62 and 47 locomotives for $20 \mathrm{kt}$ and $30 \mathrm{kt}$ heavy-loaded combined trains, respectively. Therefore, the effectiveness of the proposed model and its solution algorithm are both valid.
\end{abstract}

\section{Background}

Features of the Heavy Haul Locomotive Schedule. Compared with regular railways, the locomotive schedule of heavy haul railways has the following features [1]:

(1) The heavy-loaded trains transport much heavier goods than the regular trains. So, they need high locomotive traction and braking forces.

(2) Heavy-loaded trains generally require multilocomotive traction. For example, one $20 \mathrm{kt}$ heavy-loaded train on Da-qin Railway is hauled by two HXD locomotives.

(3) A good coordination and handling system is required for heavy haul locomotives. Da-qin Railway Co., Ltd., imported LOCOTROL technology from the United States in 2003 in order to improve the coordination of locomotive control.
(4) Heavy-loaded trains travel longer transportation distance. As a result, they require longer locomotive routing and more frequent locomotive driver shifts.

(5) The gross train weight of heavy-loaded trains is heavy, which leads to the great power between locomotives and rolling stocks and tracks.

Research Background and Significance. As shown in Figure 1, the coal demand in China increases every year with the rapid development of the economy. The demand still reaches 3.59 billion tons in 2014 even though a slight decrease is observed compared to 2013.

Da-qin Railway is the earliest double-track electrified heavy haul railway in China which carries $10 \mathrm{kt}$ and $20 \mathrm{kt}$ heavy-loaded trains. Figure 2 shows the network of Da-qin Railway. Based on Figures 1 and 2, it can be found that the freight volume of Da-qin Railway was more than 200 million 


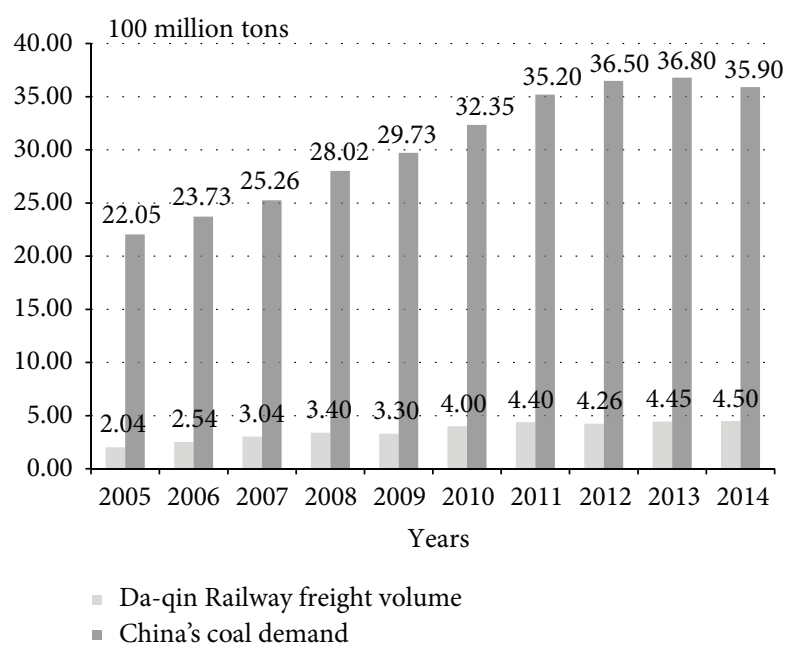

FIgure 1: China's coal demand and Da-qin Railway freight volume from 2005 to 2014 [2].

tons in 2005, which already reached the international theoretical limit of heavy haul railway transportation. Moreover, the freight volume increased to 400 million tons in 2010 and 450 million tons in 2014. However, the transported cargo volume still cannot meet the coal demand. Freight volume still needs to be improved. It is difficult to have higher freight flow density for the current train diagram and increase train's speed in Da-qin Railway. The only way to increase freight volume is to increase the transportation capacity of a train. Therefore, it needs to operate $30 \mathrm{kt}$ combined trains in Da-qin Railway.

Locomotives are a critical factor for the capacity of a railway. The locomotive schedule has a direct impact on efficiency, operation cost, and benefits of a railway. Therefore, the study on the locomotive schedule for $30 \mathrm{kt}$ combined trains in Da-qin Railway is necessary.

Background of Heavy Haul Locomotive Schedule. Research on heavy haul locomotives mainly concentrates on the technical level. Cheng et al. [3] provided technical support for the application of Reliability Centered Maintenance (RCM) in railway locomotive and verified its effectiveness in keeping reliability and reducing maintenance cost. Zheng and Wei [4], Chang [5], and Mu et al. [6] analyzed the mechanical response of railway track structure under axle loads from $25 \mathrm{t}$ to $40 \mathrm{t}$. Raviv and Kaspi [7] and Kumar and Bierlaire [8] proposed a mixed integer linear model that determines the optimal strategy. Studies on optimal locomotive schedule are quite few, because of the small density of heavy-loaded trains, short length of station track, and the difficult transportation organization. Meanwhile, these researches of heavy haul locomotives are mainly for 10 20 kt heavy-loaded trains. Relatively speaking, researches on the operational level are mainly about regular railways, which focus on the following areas: (1) Ji et al. [9] used computer technologies to achieve double-locomotive traction control and determine locomotive marshalling schedules; (2) Ruppert et al. [10] analyzed how to increase the usage efficiency and reliability of locomotives; (3) Kuo and Nicholls [11] developed a mixed integer linear program (MILP) to determine the least-cost plan of allocating locomotives and improve locomotive utilization; (4) Aronsson et al. [12] built a mixed integer program (MIP) model to solve locomotive routing and scheduling problem and Vaidyanathan et al. [13] formulated the locomotive routing problem (LRP) as an integer programming problem on a suitably constructed space-time network and developed robust optimization methods to solve it; (5) Ghoseiri and Ghannadpour [14], Kasalica et al. [15], Rouillon et al. [16], and Teichmann et al. [17] were devoted to the research of locomotive assignment problem and used different methods to optimize it; and (6) Li et al. [18] established a mathematical model for generating a locomotive working diagram of a train diagram with paired trains; then they used the improved ant colony algorithm to solve it. Most of the locomotive schedule studies are for regular trains, and only a few of them involve 10 20 kt heavy-loaded trains. There are no researches of locomotive scheduling for $30 \mathrm{kt}$ heavy-loaded trains.

\section{Analysis of Locomotive Schedule for Heavy-Loaded Combined Trains on Da-qin Railway}

2.1. Organization Forms of Heavy-Loaded Trains on Da-qin Railway. There are two organization types for heavy-loaded trains on Da-qin Railway: unit type and combined type. In 2014, the daily average was 93 in the heavy-load direction on Da-qin Railway, which include 65 trains (20 kt heavyloaded combined), 12 trains (15 kt heavy-loaded combined), 13 trains (10 kt heavy-loaded combined), and 3 trains (10 kt heavy-loaded unit). The combined type is adopted for $30 \mathrm{kt}$ heavy-loaded trains.

2.2. Locomotive Utilization Method on Da-qin Railway. The uncertain railway region method is currently used to develop the heavy haul locomotive schedule on Da-qin Railway, which aims at reducing locomotive turnaround time [19]. The method can significantly improve locomotive scheduling efficiency. Figure 3 is an illustration of uncertain railroad regions locomotive utilization method.

The numbers in Figure 3 mean the running time of the corresponding section. If a locomotive which hauls a train departs from station C, after $38 \mathrm{~min}$, it will arrive at station A. In station $\mathrm{A}$, there are two traction choices to haul different trains. The locomotive utilization region of choice (a) is A$\mathrm{B}-\mathrm{D}-\mathrm{A}$ and the region of choice (b) is A-C-A. In station A, if all locomotives haul trains with the same region, there will be longer waiting time. Therefore, the uncertain railway region method can reduce locomotive turnaround time.

2.3. Criteria of Locomotive Schedule. The criteria of locomotive schedule can reflect the work quality, efficiency, and benefit of locomotives, which include quantitative criteria, quality criteria, and equilibrium criteria. The critical performance measures for these three criteria are the number of available locomotives, coefficient of locomotive requirement, and the equilibrium degree of locomotive schedule, respectively. 


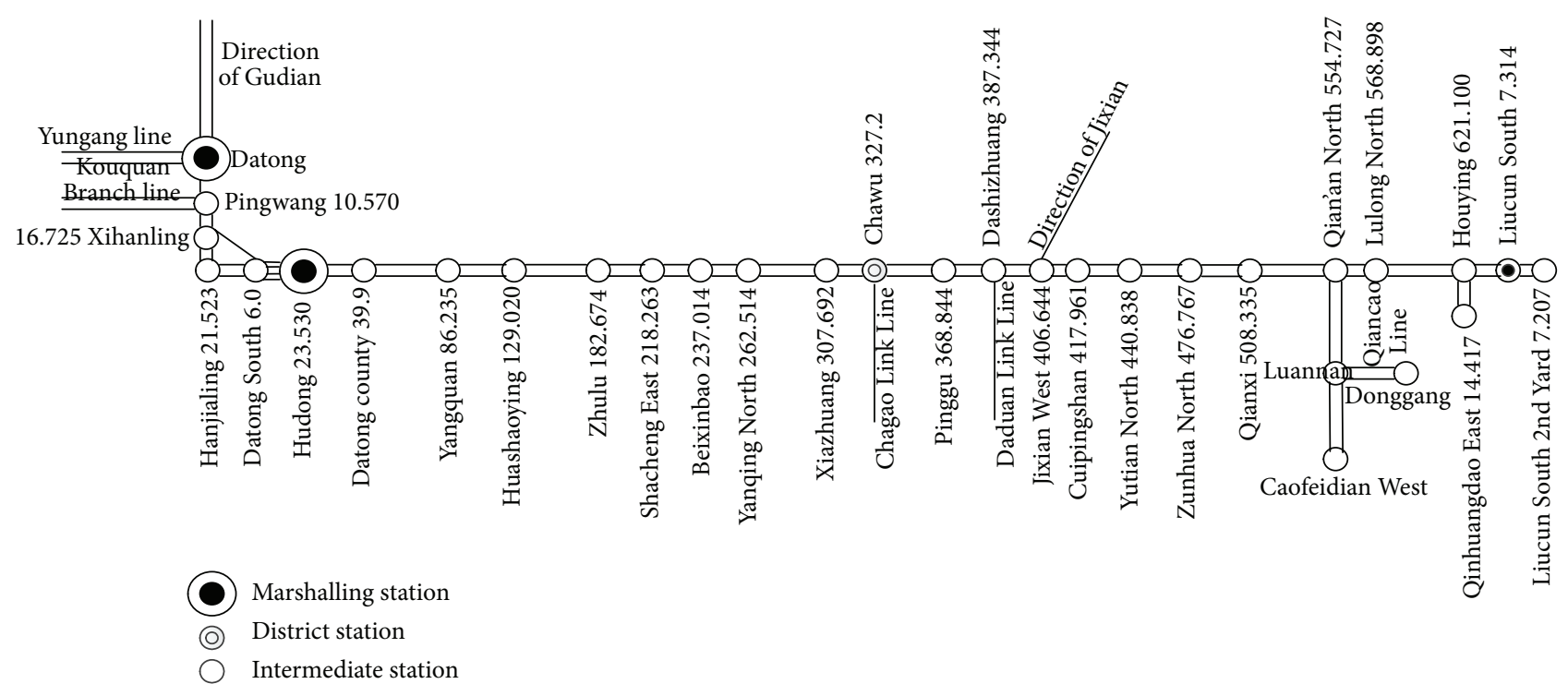

Figure 2: Network of Da-qin Railway.

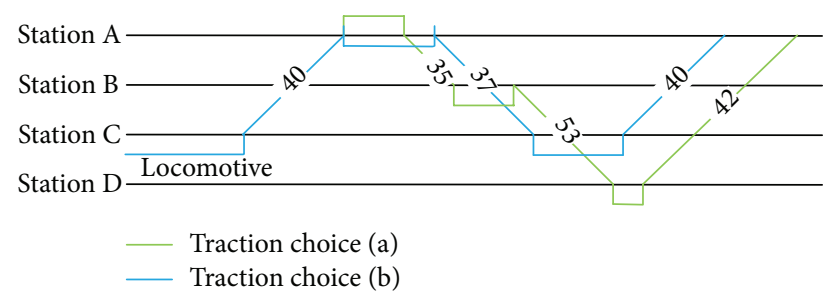

FIGURE 3: An illustration of uncertain railroad region locomotive utilization method.

(1) Number of Available Locomotives. Number of available locomotives is the total number of locomotives which are used in the whole turnaround process [20]. The less the number is, the higher the efficiency will be. The graphic method and the direct calculation method are general methods to determine the number of available locomotives. The graphic method is based on locomotive schedule to determine the number of used locomotives. The formula of direct calculation method is listed below:

$$
M_{f}=\frac{\left(n_{s}+n_{d}+2 \cdot n_{t}\right) \cdot \theta_{l}}{24}=\mu_{s} \cdot K_{d}
$$

where $M_{f}$ is the number of available locomotives in each traction section; $n_{s}$ is the total number of trains; $n_{d}$ is the number of trains with double-locomotive traction; $n_{t}$ is the number of trains with three-locomotive traction; $\theta_{l}$ is the locomotive complete turnaround time; $\mu_{s}$ is the number of supplied locomotives; $K_{d}$ is the coefficient of locomotive requirement in traction sections.

(2) Coefficient of Locomotive Requirement. The coefficient of locomotive requirement indicates the number of locomotives required per pair of trains in a traction section [20]. One locomotive completes a turnaround which means it has completed a traction task. The coefficient of locomotive requirement can be calculated by the formula below:

$$
K_{d}=\frac{\theta_{l}}{24}
$$

(3) Equilibrium Degree of Locomotive Schedule. In addition to quantitative and quality criteria, the equilibrium criteria are also very important in evaluating locomotive schedule, which refer to the difference between detention time of each locomotive at stations and running time of each locomotive. At the same section, the running time is the same. Therefore, in the actual evaluation process, the variance of detention time of each locomotive at stations, $D$ (equilibrium degree), can be used to describe the equilibrium of locomotive schedule. It can be calculated as below:

$$
D=\frac{1}{n_{l}} \sum_{i=1}^{n_{l}}\left(c_{i}-E\right)^{2},
$$

where $n_{l}$ is the total number of traction tasks of all locomotives and it is numerically equal to $\left(n_{s}+n_{d}+2 \cdot n_{t}\right) ; i$ is a locomotive that undertakes traction tasks; that is, $i \in n_{l} ; c_{i}$ is the detention time of a locomotive at station; $E$ is the average detention time of locomotives at stations.

Equation (3) shows that equilibrium degree $D$ refers to the discrete degree between $c_{i}\left(i=1,2,3, \ldots, n_{l}\right)$ and $E$. The smaller the value of $D$ is, the smaller the difference is and the more balanced the locomotive schedule will be.

\section{The Optimization Model of Heavy Haul Locomotive Scheduling Problem}

3.1. Description of Locomotive Scheduling Problem. The inputs for the locomotive scheduling problem are railway line, locomotive traction sections and train diagram, and so forth. Based on these input data, the output, namely, locomotive schedule, can be obtained. 


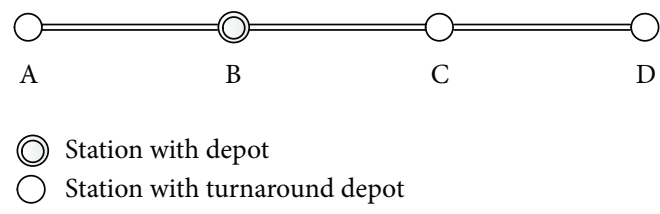

FIgURE 4: The network of hypothetical railway line.

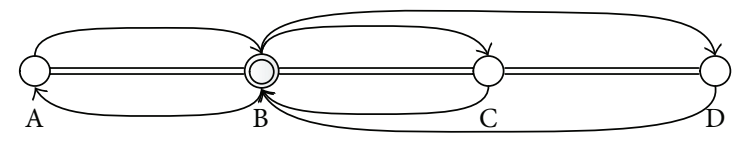

FIGURE 5: Schematic diagram of locomotive traction sections.

\subsubsection{Input}

(1) Railway Line. Railway line A-B-C-D is a double-track railway as shown in Figure 4. It is dedicatedly used to transport coal. On the railway, station $\mathrm{B}$ is the station where the locomotive depot is located. Station A, station C, and station $\mathrm{D}$ are the stations where locomotive turnaround depots are located.

(2) Locomotive Traction Sections. When freight locomotives undertake traction tasks in section A-D, they firstly depart from station $B$ and haul heavy-loaded trains to arrive at station A, station C, or station D. Then judge whether locomotive preparation is needed or not. Finally these locomotives haul empty-wagon trains and return to the station where the locomotive depot is located, while the locomotives which are at turnaround depot can haul the return trains only. The schematic diagram of locomotive traction sections is shown in Figure 5.

(3) Train Diagram. A complete train diagram determines train routes, departure/arrival time, and detention time at each station. In the train diagram, we cannot know the locomotive's position and which train it will haul. As shown in Figure 6 , there are 4 pairs of trains on the hypothetical railway (4 heavy-loaded trains and 4 empty-wagon trains). The train numbers, respectively, are 70001/2, 73001/2, 73003/4, and $79001 / 2$. The train whose train number is 70001 refers to a heavy-loaded train in section $\mathrm{A}-\mathrm{B}$, and the train whose train number is 70002 refers to an empty-wagon train in section A$B$. The train whose train number is 73001 or 73003 refers to a heavy-loaded train in section $\mathrm{B}-\mathrm{C}$, and the train whose train number is 73002 or 73004 refers to an empty-wagon train in section B-C. The train whose train number is 79001 refers to a heavy-loaded train in section $\mathrm{D}-\mathrm{B}$, and the train whose train number is 79002 refers to an empty-wagon train in section D-B.

3.1.2. Output. Based on the input data, the potential locomotive schedule in section A-D will be obtained (see Figure 7), where a dotted line represents a locomotive. Figure 7 shows that, after hauling the train whose train number is 70001 to station $\mathrm{B}$, the locomotive can haul the train whose train number is 70002, 79001, or 73001. When multilocomotive traction schemes exist, the minimal detention time of locomotives at stations will be adopted to determine the final scheme.

3.2. Model Description. Some assumptions are presented in this model: (a) the train diagram is known and invariant in a certain period of time; that is, the impact of train delay will be ignored; (b) based on the line length of Da-qin Railway $(653 \mathrm{~km})$, locomotive routing and locomotive running time (e.g., a round-trip time more than $17 \mathrm{~h}$ ), it assumes within 24 hours all available locomotives (the total locomotives after deducting the locomotives in maintenance and preparation) are without maintenance; (c) for the trains with multilocomotive traction, locomotive reconnection between HXD locomotives and SS4 locomotives is not considered; the time of locomotive reconnection and dismantling was included in the detention time of locomotives at stations; (d) in a certain period of time, the locomotive crew working system in Da-qin Railway is invariant, so the effects of locomotive crew working system and locomotive crew shift mode on locomotive scheduling are not considered; and (e) in the daily initial time (18:00) each station has enough locomotives which at least are equal to the number of locomotives in need; that is, the locomotive homing will not be considered.

3.2.1. Sets. In the process of constructing the optimization model of the heavy haul locomotive scheduling problem, there are some notations and sets that will be used:

$K$ is the set that includes all of stations on the railway; $k$ is a station on the railway; that is, $k \in K$;

$N_{k, d}$ is the total number of locomotives arriving at station $k$;

$N_{k, f}$ is the total number of trains departing from station $k$;

$i$ is the locomotive arriving at station $k$;

$j$ is the train departing from station $k$;

$T_{k}$ is the minimal technological time of locomotives at station $k$;

$k_{i, d}$ is the destination station of locomotive $i$ at station $k$;

$t_{i, d, k}$ is the arrival time of locomotive $i$ at station $k$;

$k_{j, f}$ is the departure station of train $j$ from station $k$;

$t_{j, f, k}$ is the departure time of train $j$ from station $k$.

3.2.2. Parameters. In the process of developing the optimization model, the known parameter that will be involved is $c_{i, j}^{k}$. It refers to the waiting time which is equal to the detention time of locomotive $i$ at station $k$ minus the minimal 


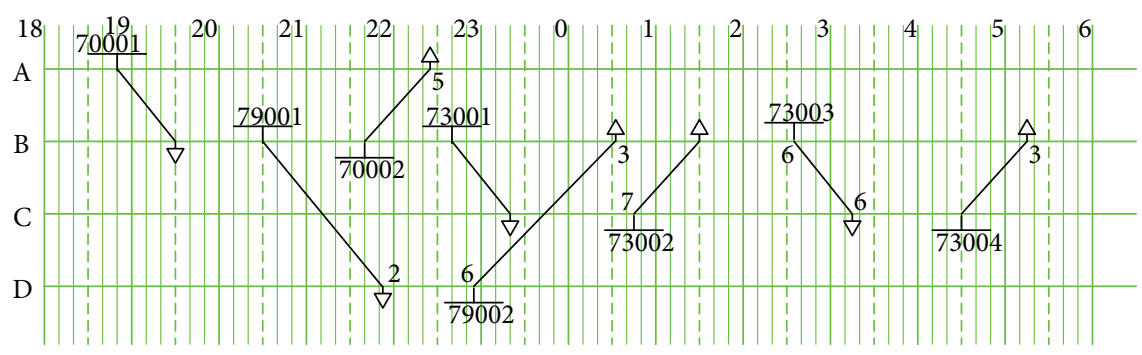

Figure 6: Train diagram in section A-D.

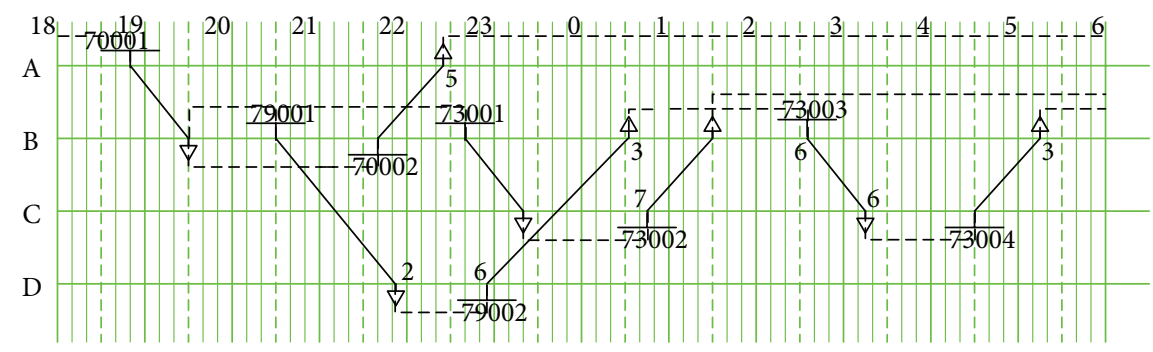

FIGURE 7: Potential locomotive schedule in section A-D.

technological time. The waiting time $c_{i, j}^{k}$ of locomotives at stations can be calculated by

$$
\begin{aligned}
& c_{i, j}^{k} \\
& = \begin{cases}t_{j, f, k}-t_{i, d, k}-T_{k}, & t_{j, f, k}-t_{i, d, k} \geq T_{k}, k_{i, d}=k_{j, f}, \\
t_{j, f, k}-t_{i, d, k}-T_{k}+1440, & t_{j, f, k}-t_{i, d, k}<T_{k}, k_{i, d}=k_{j, f}, \\
\infty, & k_{i, d} \neq k_{j, f} .\end{cases}
\end{aligned}
$$

3.2.3. Variable. The variable is assumed to be $c_{i, j}^{k}$, which refers to whether locomotive $i$ hauls train $j$ or not at station $k$. The binary variable $c_{i, j}^{k}$ is defined as follows:

$$
x_{i, j}^{k}= \begin{cases}1, & \text { locomotive } i \text { hauls train } j \text { at station } k \\ 0, & \text { otherwise }\end{cases}
$$

3.2.4. Objective Function. Completing planned traction tasks is the primary constraint to us. Based on that, the less the number of locomotives is, the lower the transportation cost will be. Therefore, the objective function of heavy haul locomotive scheduling problem is minimizing number of locomotives; that is,

$$
\min Z^{\prime}=\frac{T_{t}+T}{1440},
$$

where $T_{t}$ is the total time of trains running from departure station to destination station and $T$ is the total detention time of locomotives at stations, which can be calculated by

$$
T=T_{K}+T_{w}
$$

where $T_{K}$ is the total minimal technological time of locomotives at stations and $T_{w}$ is the total waiting time of locomotives at stations.
For the established train diagram, $T_{t}$ is a constant. So the minimum number of locomotives refers to the minimal detention time $T$ of locomotives at stations. Meanwhile, $T_{K}$ is also a constant. So the minimal detention time of locomotives at stations refers to the minimum waiting time $T_{w}$ of locomotives at stations. That is,

$$
\min Z=T_{w}=\sum_{k=1}^{K} \sum_{i=1}^{N_{k, d}} \sum_{j=1}^{N_{k, f}} c_{i, j}^{k} x_{i, j}^{k}
$$

Then the equilibrium degree $D$ of locomotive schedule can be calculated by

$$
\begin{aligned}
D= & \frac{1}{n_{s}+n_{d}+2 \cdot n_{t}} \\
& \cdot \sum_{k=1}^{K} \sum_{i=1}^{N_{k, d}} \sum_{j=1}^{N_{k, f}}\left(c_{i, j}^{k} x_{i, j}^{k}-\frac{Z}{n_{s}+n_{d}+2 \cdot n_{t}}\right)^{2} .
\end{aligned}
$$

\subsubsection{Constraints}

(1) Traction Locomotives Constraint. Consider the following:

$$
\sum_{i=1}^{N_{k, d}} x_{i, j}^{k}=h, \quad \forall j \in N_{k, f}, \quad \forall k \in K .
$$

This constraint shows that the number of traction locomotives for each train is $h$. The value of each type of train is shown in Table 1.

(2) Traction Tasks Constraint. Consider the following:

$$
\sum_{j=1}^{N_{k, f}} x_{i, j}^{k}=1, \quad \forall i \in N_{k, d}, \quad \forall k \in K .
$$


TABLE 1: The value of each type of trains.

\begin{tabular}{lccc}
\hline Types of heavy-loaded trains & Reference value & Types of heavy-loaded trains & Reference value \\
\hline $10 \mathrm{kt}$ heavy-loaded combined trains & 2 & $20 \mathrm{kt}$ heavy-loaded combined trains & 2 \\
$10 \mathrm{kt}$ heavy-loaded unit trains & 1 & $30 \mathrm{kt}$ heavy-loaded combined trains & 3 \\
$15 \mathrm{kt}$ heavy-loaded combined trains & 2 & - & - \\
\hline
\end{tabular}

This constraint shows that each locomotive can only haul one train at the same time.

\section{Transformation and Solving Processes of Heavy Haul Locomotive Scheduling Problem}

First of all, the locomotive scheduling problem needs to be transformed into an assignment problem. Then the optimization results are obtained by using the Hungarian algorithm.

\subsection{Transformation of Heavy Haul Locomotive Scheduling} Problem. For an unpaired train diagram, the number of arrival trains is not equal to the number of departure trains at some stations. So the unpaired train diagram needs to be transformed into a paired train diagram before solving the locomotive scheduling problem. For the paired train diagram, the number of arrival trains is equal to the number of departure trains at each station. Therefore, if each train is hauled by the same type of locomotive, the locomotive scheduling problem can be transformed into a standard assignment problem by treating arrival locomotives as "personnel" and departure trains as "missions."

Therefore, the transformation of heavy haul locomotive scheduling problem mainly focuses on the following three aspects.

(1) Transforming Unpaired Train Diagram into Paired Train Diagram. Usually, the train will be operated smoothly according to the train diagram. Because the number of trains in train diagram is given on the known railway, the number of trains within $24 \mathrm{~h}$ is determined. If the train diagram is unpaired, it needs to add some "virtual operation curves." Then the number of arrival trains is equal to the number of departure trains in each section. It assumes that the number of "virtual operation curves" is $Y$ and the number of actual trains is $J$.

(2) Transforming Multilocomotive Traction into SingleLocomotive Traction. If the total number of trains is $Y+J$, the number of trains with double-locomotive traction is $W$ and the number of trains with three-locomotive traction is $V(W+V \leq J+Y)$. Then the number of "virtual trains" is $W+2 V$ when multilocomotive traction is transformed into single-locomotive traction. At the same time, it needs to ensure that the information of train diagram is consistent with before. Then trains will be sorted and coded according to departure times, and the code of trains may be $1,2,3, \ldots$, $J+Y+W+2 V-2, J+Y+W+2 V-1, J+Y+W+2 V$.

(3) Transformation between Different Locomotive Types. There are two locomotive types which include SS4 locomotive and
HXD locomotive in Da-qin Railway. 10 kt heavy-loaded combined trains are hauled by SS4 locomotives while $10 \mathrm{kt}$ heavyloaded unit trains, $15 \mathrm{kt}$ heavy-loaded combined trains, and $20 \mathrm{kt}$ heavy-loaded combined trains are hauled by HXD locomotives. There is no locomotive reconnection between HXD locomotives and SS4 locomotives. Therefore, locomotive scheduling problem which involves two locomotive types can be considered separately for each type in order to obtain the optimal solutions. Then, the optimization objective of the locomotive schedule on the whole railway is achieved.

4.2. Solution Algorithm of Heavy Haul Locomotive Schedule. In this paper, the optimization model of heavy haul locomotive schedule is solved by using Hungarian algorithm. The Hungarian algorithm, as a classical algorithm, can obtain a global optimal solution when it is used to solve assignment problems. With an increasing coefficient matrix dimension, the algorithm runs a little slower, but it can reduce computational efforts much more than any enumeration method [22]. The concrete steps of Hungarian algorithm are as follows.

Step 1 (generating coefficient matrix). The coefficient matrix of detention time of locomotives at stations for each station is built firstly, and then the coefficient matrix for whole railway can be built.

Step 2 (transforming coefficient matrix). When performing the row operations on the coefficient matrix, we subtract the lowest value from each element in that row in order to obtain at least one zero element for each row. Similarly, we also do this procedure for all column elements.

Step 3 (seeking independent zero elements). If the number of independent zero elements is less than the order of the coefficient matrix, then go to Step 4. If the number of independent zero elements is equal to the order of the coefficient matrix, then output the optimization solution and end the algorithm.

Step 4 (drawing the least number of straight lines). If the number of straight lines is less than the order of the coefficient matrix, then mark the rows and columns and go to Step 5; otherwise, go to Step 3.

Step 5 (transforming coefficient matrix again). Seek minimum value of the elements which are not covered by straight lines. This value is then subtracted from each element in all marked rows and added to each element in the marked columns, and then go to Step 3.

The flow chart of the Hungarian algorithm is shown in Figure 8. 


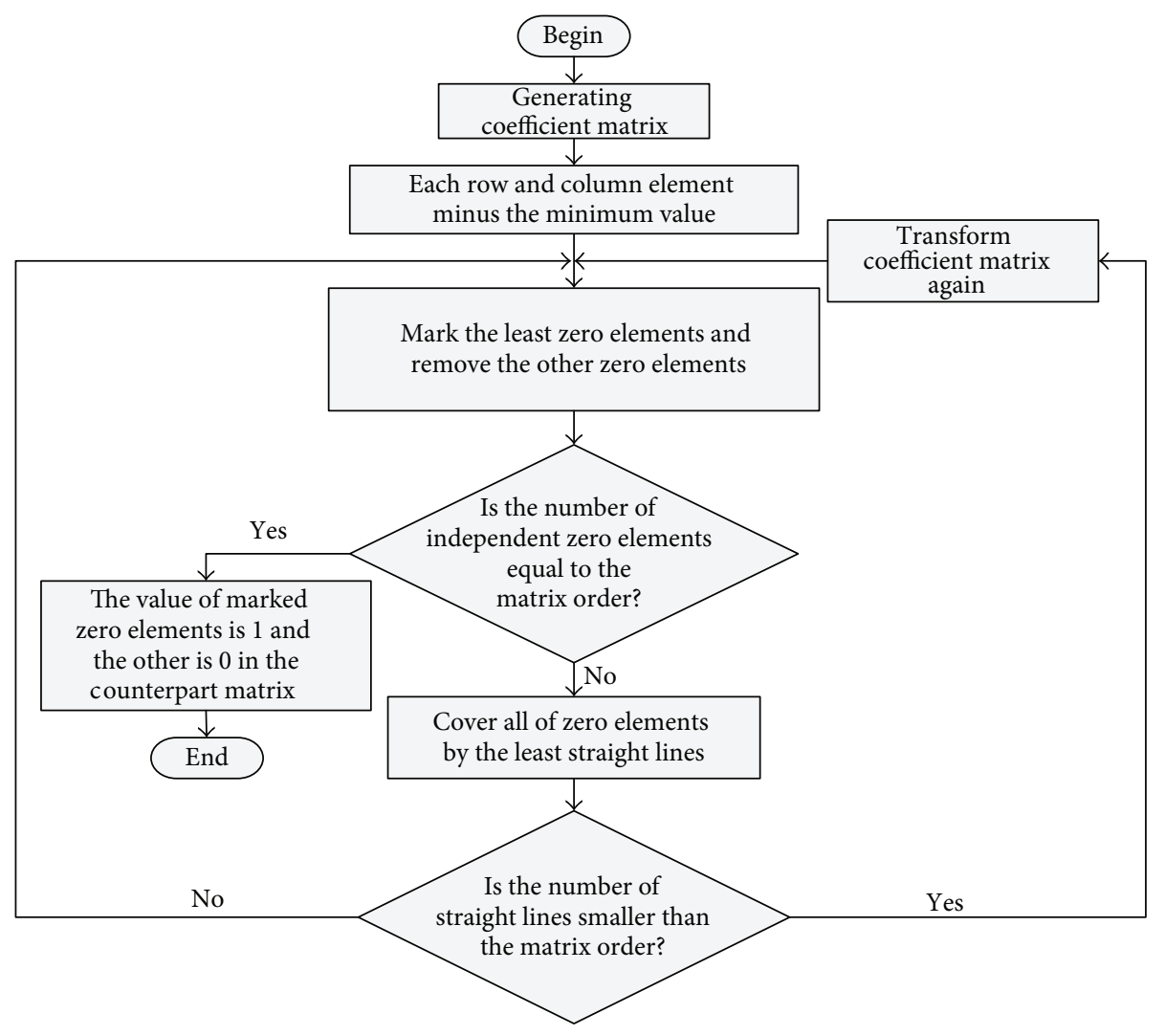

FIgURE 8: Flow chart of the Hungarian algorithm.

\section{Case Study}

5.1. Evaluating the Feasibility of Heavy Haul Locomotive Schedule Model. The model and its solution algorithm need to be validated before applying them to any real problems.

5.1.1. Data Source and Processing. As shown in Figure 4, line A-B-C-D is a double-track railway (section A-D for short) which is specially used to transport coal. Station B is the station where the locomotive depot is located, and the minimal technological time of locomotives at stations is 125 min. Station A, station C, and station D are the stations where locomotive turnaround depots are located, and the minimal technological time of locomotives at stations is $50 \mathrm{~min}$. There are 8 trains ( 4 pairs) which include 2 trains ( 1 pair) in section A-B, 4 trains (2 pairs) in section B-C, and 2 trains (1 pair) in section B-D on the railway. If all of trains are hauled by single-locomotive, Figure 6 is the train diagram.

This basic data needs to be processed as follows.

(1) Stations Coding. For all stations in section A-D, it can code stations from any end of the railway and it starts with station A.

(2) Trains Coding. The trains in section A-D are sole. However, it is necessary for each train to code another sole and
TABLE 2: Trains coding result in section A-D.

\begin{tabular}{lccc}
\hline Train number & Train coding & Train number & Train coding \\
\hline 70001 & 1 & 73003 & 5 \\
70002 & 2 & 73004 & 6 \\
73001 & 3 & 79001 & 7 \\
73002 & 4 & 79002 & 8 \\
\hline
\end{tabular}

simple number due to the long and large train number. The coding results are listed in Table 2.

(3) Time Simplification. For the departure time and arrival time of each train, starting at the initial time (18:00) of the train diagram, time of $24 \mathrm{~h}$ can be converted to minutes, and, for example, 19:33 can be converted to the 93rd minute.

(4) Generating Coefficient Matrix. According to (4), the coefficient matrix $c_{i, j}^{k}$ of the detention time of locomotives at stations will be generated by using C\#. The results are listed below.

Station A. Consider the following:

$$
c_{2,1}^{\mathrm{A}}=50-265-50+1440=1175,
$$

$$
(50-265=-215<50) \text {. }
$$


Station B. Consider the following:

$$
\begin{aligned}
& c_{1,2}^{\mathrm{B}}=220-90-125=5, \quad(220-90=130>125), \\
& c_{1,3}^{\mathrm{B}}=280-90-125=65, \quad(280-90=190>125), \\
& c_{1,5}^{\mathrm{B}}=516-90-125=301, \\
& \quad(516-90=426>125), \\
& c_{1,7}^{\mathrm{B}}=150-90-125+1440=1375, \\
& \quad(150-90=60<125) ; \\
& c_{4,2}^{\mathrm{B}}=220-450-125+1440=1085,
\end{aligned}
$$$$
(220-450=-230<125),
$$$$
c_{4,3}^{\mathrm{B}}=280-450-125+1440=1145,
$$$$
(280-450=-170<125),
$$$$
c_{4,5}^{\mathrm{B}}=516-450-125+1440=1381,
$$$$
(516-450=66<125516-450=66<125),
$$$$
c_{4,7}^{\mathrm{B}}=150-450-125+1440=1015,
$$$$
(150-450=-300<125) ;
$$$$
c_{6,2}^{\mathrm{B}}=220-673-125+1440=862 \text {, }
$$$$
(220-673=-453<125),
$$$$
c_{6,3}^{\mathrm{B}}=280-673-125+1440=922,
$$$$
(280-673=-393<125),
$$$$
c_{6,5}^{\mathrm{B}}=516-673-125+1440=1158,
$$$$
(516-673=-157<125),
$$$$
c_{6,7}^{\mathrm{B}}=150-673-125+1440=792,
$$$$
(150-673=-523<125) ;
$$$$
c_{8,2}^{\mathrm{B}}=220-363-125+1440=1172,
$$$$
(220-363=-143<125),
$$

$$
c_{8,3}^{\mathrm{B}}=280-363-125+1440=1232,
$$

\begin{tabular}{|c|c|c|c|c|c|c|c|c|}
\hline \multirow{2}{*}{$i$} & \multicolumn{8}{|c|}{$j$} \\
\hline & 1 & 2 & 3 & 4 & 5 & 6 & 7 & 8 \\
\hline 1 & $\infty$ & 5 & 65 & $\infty$ & 301 & $\infty$ & 1375 & $\infty$ \\
\hline 2 & 1175 & $\infty$ & $\infty$ & $\infty$ & $\infty$ & $\infty$ & $\infty$ & $\infty$ \\
\hline 3 & $\infty$ & $\infty$ & $\infty$ & 37 & $\infty$ & 260 & $\infty$ & $\infty$ \\
\hline 4 & $\infty$ & 1085 & 1145 & $\infty$ & 1381 & $\infty$ & 1015 & $\infty$ \\
\hline 5 & $\infty$ & $\infty$ & $\infty$ & 1241 & $\infty$ & 24 & $\infty$ & $\infty$ \\
\hline 6 & $\infty$ & 862 & 922 & $\infty$ & 1158 & $\infty$ & 792 & $\infty$ \\
\hline 7 & $\infty$ & $\infty$ & $\infty$ & $\infty$ & $\infty$ & $\infty$ & $\infty$ & 14 \\
\hline 8 & $\infty$ & 1172 & 1232 & $\infty$ & 28 & $\infty$ & 1102 & $\infty$ \\
\hline
\end{tabular}

$$
(280-363=-83<125),
$$

$c_{8,5}^{\mathrm{B}}=516-363-125=28$,

$$
(516-363=153>125),
$$$$
c_{8,7}^{\mathrm{B}}=150-363-125+1440=1102,
$$$$
(150-90=-213<125) .
$$

TABle 3: Coefficient matrix of detention time of locomotives at stations.

Station C. Consider the following:

$$
\begin{aligned}
& c_{3,4}^{\mathrm{C}}=407-320-50=37, \quad(407-320=87>50), \\
& c_{3,6}^{\mathrm{C}}=630-320-50=260, \\
& \quad(630-320=310>50) ; \\
& c_{5,4}^{\mathrm{C}}=407-556-50+1440=1241, \\
& \quad(407-556=-149<50), \\
& c_{5,6}^{\mathrm{C}}=630-556-50=24, \quad(630-556=74>50) .
\end{aligned}
$$

Station D. Consider the following:

$$
c_{7,8}^{\mathrm{D}}=296-232-50=14, \quad(296-232=64>50) .
$$

The others are equal to $\infty$; the coefficient matrix $\left(c_{i, j}^{k}\right)$ is showed in Table 3.

5.1.2. Result. The Hungarian algorithm is implemented in MATLAB and the optimal locomotive schedule is as follows.

The minimum waiting time of locomotives at stations is

$$
\begin{aligned}
T_{w} & =Z=\sum_{k=1}^{4} \sum_{i=1}^{8} \sum_{j=1}^{8} c_{i, j}^{k} x_{i, j}^{k} \\
& =65+1175+37+1085+24+792+14+28 \\
& =3220(\min ) .
\end{aligned}
$$
is

The minimal technological time of locomotives at stations

$$
T_{K}=125 \times 4+50 \times 4=700(\mathrm{~min}) .
$$

The running time of locomotives is

$$
\begin{aligned}
T_{t} & =40+45+40+43+40+43+82+67 \\
& =400(\mathrm{~min}) .
\end{aligned}
$$

The minimum number of locomotives is

$$
\begin{aligned}
M & =\frac{T_{t}+T}{1440}=\frac{T_{t}+T_{K}+T_{w}}{1440}=\frac{400+700+3220}{1440} \\
& =\frac{4320}{1440}=3 .
\end{aligned}
$$




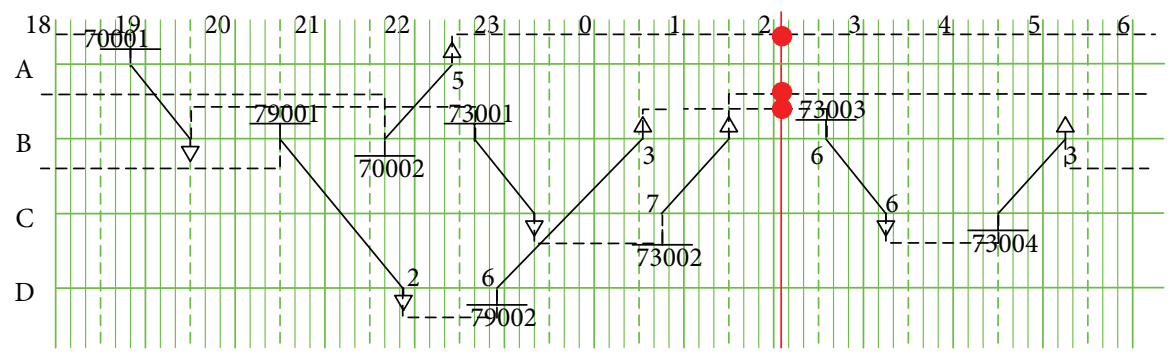

FiguRE 9: Locomotive schedule in section A-D.

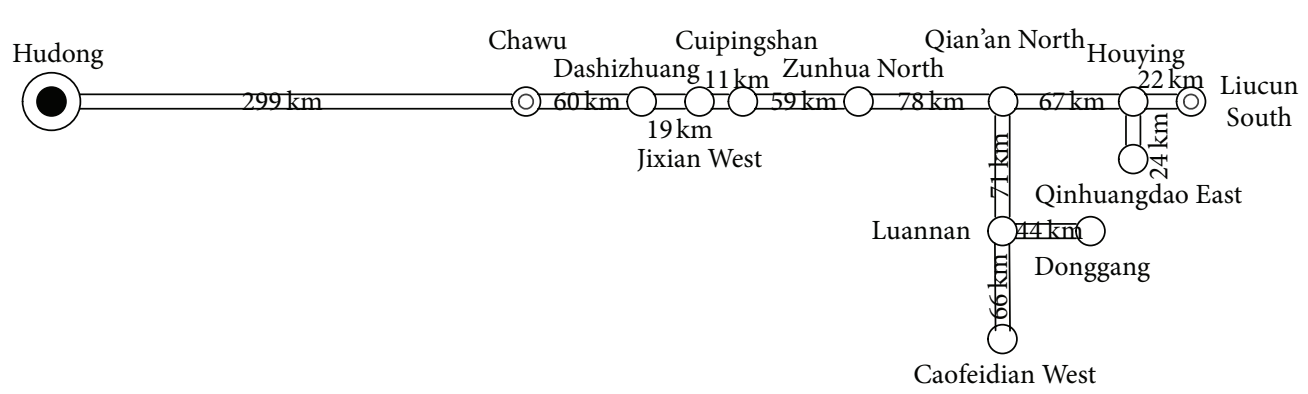

Figure 10: The simplified network of Da-qin Railway.

The coefficient of locomotive requirement is

$$
K_{d}=\frac{M}{n}=\frac{3}{8 / 2}=0.75 .
$$

The locomotive schedule can be expressed as an intuitive diagram, which is shown in Figure 9 (dotted lines represent locomotives and solid lines represent trains).

Figure 9 shows that there are 3 traction locomotives, which are equal to the calculation result, to haul trains.

\subsubsection{Result Analysis}

(1) Analysis on the Optimization of Locomotive Scheduling. Figures 7 and 9 show that there may be a variety of train connections. So, the number of available locomotives and coefficient of locomotive requirement are uncertain. The optimization model of heavy-loaded locomotive schedule is established and then it can be solved by Hungarian algorithm. It can not only make sure of the uniqueness of locomotive traction tasks, but also complete established traction tasks with a minimum number of locomotives.

(2) Analysis on the Equilibrium of Locomotive Schedule. The equilibrium degree of locomotive schedule of Figure 9 can be obtained by using (9), which is

$$
\begin{aligned}
D & =\frac{1}{8} \sum_{k=1}^{4} \sum_{i=1}^{8} \sum_{j=1}^{8}\left(c_{i, j}^{k} x_{i, j}^{k}-\frac{Z}{8}\right)^{2}=\frac{1}{8}\left[\left(65-\frac{3220}{8}\right)^{2}\right. \\
& +\left(1175-\frac{3220}{8}\right)^{2}+\left(37-\frac{3220}{8}\right)^{2} \\
& +\left(1085-\frac{3220}{8}\right)^{2}+\left(24-\frac{3220}{8}\right)^{2}
\end{aligned}
$$

$$
\begin{aligned}
& +\left(792-\frac{3220}{8}\right)^{2}+\left(14-\frac{3220}{8}\right)^{2} \\
& \left.+\left(28-\frac{3220}{8}\right)^{2}\right]=237027 .
\end{aligned}
$$

It shows that the equilibrium degree of locomotive schedule is large. The main reason is that there are no trains from 6:00 to 18:00 on the railway. Therefore, the difference between the detention time of locomotives at stations from 18:00 to 6:00 the next day and the detention time of locomotives at stations from 6:00 to 18:00 is relatively large. If there are trains from 6:00 to 18:00, the equilibrium degree of locomotive schedule will be reduced and the locomotive schedule will be more balanced.

5.2. Analysis of Locomotive Schedule for $20 \mathrm{kt}$ Combined Trains on Da-qin Railway. The previous section shows that the model of locomotive schedule is feasible. Then, the effectiveness of the proposed model also needs to be validated which is conducted in this section.

5.2.1. Line Simplification. Da-qin Railway has 26 stations and the line length is $653 \mathrm{~km}$; Qiancao Railway has 5 stations and the line length is $137 \mathrm{~km}$. Jingtang Port-Donggang Railway Line has 5 stations and the line length is $45 \mathrm{~km}$. Some intermediate stations on the railway do not have the technical operation, so they are not displayed. Only the stations where locomotive depot or turnaround depot is located are considered. The simplified network of Da-qin Railway is shown in Figure 10.

Hudong station is the station where the locomotive depot is located, and the minimal technological time of locomotives 
at stations is $250 \mathrm{~min}$. Liucun South station, Donggang station, Caofeidian West station, and Qinhuangdao East station are the stations where locomotive turnaround depots are located. The minimal technological time of locomotives at stations for Liucun South station is $220 \mathrm{~min}$. The minimal technological time of locomotives at stations for Donggang station and Caofeidian West station is $100 \mathrm{~min}$. The minimal technological time of locomotives at stations for Qinhuangdao East station is $125 \mathrm{~min}$. The minimal technological time of the other stations where the locomotives turn back is $50 \mathrm{~min}$.

There were 100 heavy-loaded trains in the heavy-load direction and 104 empty-wagon trains in the reverse direction on December 10, 2014.

5.2.2. Data Processing. In reference to the mentioned method, complete the data processing. For the HXD locomotives, there are 328 trains which are hauled by singlelocomotive after conversion, so the order of the coefficient matrix is 328. For the SS4 locomotives, there are 56 trains which are hauled double-locomotive after conversion, so the order of the coefficient matrix is 56. In this paper, C\# is employed to deal with such huge data.

\subsubsection{Result. The results are illustrated as follows.}

The minimum waiting times of locomotives at stations are, respectively,

$$
\begin{aligned}
Z_{\mathrm{HXD}} & =\sum_{k=1}^{13} \sum_{i=1}^{328} \sum_{j=1}^{328} c_{i, j}^{k} x_{i, j}^{k}=37116(\mathrm{~min}), \\
Z_{\mathrm{SS} 4} & =\sum_{k=1}^{13} \sum_{i=1}^{56} \sum_{j=1}^{56} c_{i, j}^{k} x_{i, j}^{k}=10409(\mathrm{~min}) .
\end{aligned}
$$

The minimal technological times of locomotives at stations are, respectively,

$$
\begin{aligned}
T_{K}^{\mathrm{HXD}}= & 164 \times 250+76 \times 220+14 \times 125+44 \times 100 \\
& +30 \times 50=65370(\mathrm{~min}) \\
T_{K}^{\mathrm{SS} 4}= & 28 \times 250+28 \times 50=8400(\mathrm{~min})
\end{aligned}
$$

The running times of locomotives are, respectively,

$$
\begin{aligned}
T_{t}^{\mathrm{HXD}} & =198474(\mathrm{~min}), \\
T_{t}^{\mathrm{SS} 4} & =24391(\mathrm{~min}) .
\end{aligned}
$$

According to that data, the minimum numbers of locomotives are, respectively,

$$
\begin{aligned}
M_{\mathrm{HXD}} & =\frac{T_{t}+T}{1440}=\frac{T_{t}+T_{K}+Z}{1440} \\
& =\frac{198474+65370+37116}{1440}=\frac{300960}{1440}=209,
\end{aligned}
$$

$$
\begin{aligned}
M_{\text {SS } 4} & =\frac{T_{t}+T}{1440}=\frac{T_{t}+T_{K}+Z}{1440} \\
& =\frac{24391+8400+10409}{1440} \times 2=\frac{43200}{1440} \times 2 \\
& =60 .
\end{aligned}
$$

So, the coefficients of locomotive requirement are, respectively,

$$
\begin{aligned}
K_{d}^{\mathrm{HXD}} & =\frac{M_{\mathrm{HXD}}}{n}=\frac{209}{160 / 2}=2.61, \\
K_{d}^{\mathrm{SS} 4} & =\frac{M_{\mathrm{SS} 4}}{n}=\frac{30 \times 2}{56 / 2}=2.14 .
\end{aligned}
$$

According to the best connection matrix, locomotive connection scheme for $20 \mathrm{kt}$ combined trains on Da-qin Railway can be obtained. The locomotive connection scheme of SS4 locomotives is as follows:

$$
\begin{aligned}
& \mathrm{H} 16012 \longrightarrow 52 \text { (single-locomotive) } \longrightarrow \mathrm{H} 16016 \\
& \longrightarrow 54 \text { (single-locomotive) } \longrightarrow \mathrm{H} 16004 \\
& \longrightarrow \mathrm{H} 19609 \longrightarrow \mathrm{H} 19504 \longrightarrow \mathrm{H} 19605 \\
& \longrightarrow \mathrm{H} 19512 \longrightarrow 53 \text { (single-locomotive) } \\
& \longrightarrow \mathrm{H} 16018 \longrightarrow 56 \text { (single-locomotive) } \\
& \longrightarrow \mathrm{H} 16002 \longrightarrow 48 \text { (single-locomotive) } \\
& \longrightarrow \mathrm{H} 15506 \longrightarrow 47 \text { (single-locomotive) } \\
& \longrightarrow \mathrm{H} 16010 \longrightarrow 19601 \longrightarrow \mathrm{H} 19508 \\
& \longrightarrow 46 \text { (single-locomotive) } \longrightarrow \mathrm{H} 16008 \\
& \longrightarrow \mathrm{H} 15501 \longrightarrow \mathrm{H} 15504 \longrightarrow \mathrm{H} 19607 \\
& \longrightarrow \mathrm{H} 19516 \longrightarrow 19615 \longrightarrow \mathrm{H} 19514 \\
& \longrightarrow \mathrm{H} 28501 \longrightarrow \mathrm{H} 28510 \\
& \longrightarrow 51 \text { (single-locomotive) } \longrightarrow \text { H16014 } \\
& \longrightarrow \mathrm{H} 19603 \longrightarrow \mathrm{H} 19502 \longrightarrow \mathrm{H} 28507 \\
& \longrightarrow \mathrm{H} 28512 \longrightarrow 49 \text { (attached locomotive) } \\
& \longrightarrow \mathrm{H} 15508 \longrightarrow \mathrm{H} 28503 \longrightarrow \mathrm{H} 28508 \\
& \longrightarrow 50 \text { (single-locomotive) } \longrightarrow \mathrm{H} 16012 \\
& \longrightarrow \mathrm{H} 19611 \longrightarrow \mathrm{H} 19506 \longrightarrow \mathrm{H} 28511 \\
& \longrightarrow \mathrm{H} 28502 \longrightarrow \mathrm{H} 15503 \longrightarrow \mathrm{H} 15502 \\
& \longrightarrow 55 \text { (attached locomotive) } \longrightarrow \mathrm{H} 15510 \\
& \longrightarrow \mathrm{H} 28505 \longrightarrow \mathrm{H} 28506 \\
& \longrightarrow 45 \text { (single-locomotive) } \longrightarrow \mathrm{H} 16006 \\
& \longrightarrow \mathrm{H} 19611 \text {; } \\
& \mathrm{H} 19613 \longrightarrow \mathrm{H} 19510 \longrightarrow \mathrm{H} 19613 ; \\
& \mathrm{H} 28504 \longrightarrow \mathrm{H} 28509 \longrightarrow \mathrm{H} 28504
\end{aligned}
$$




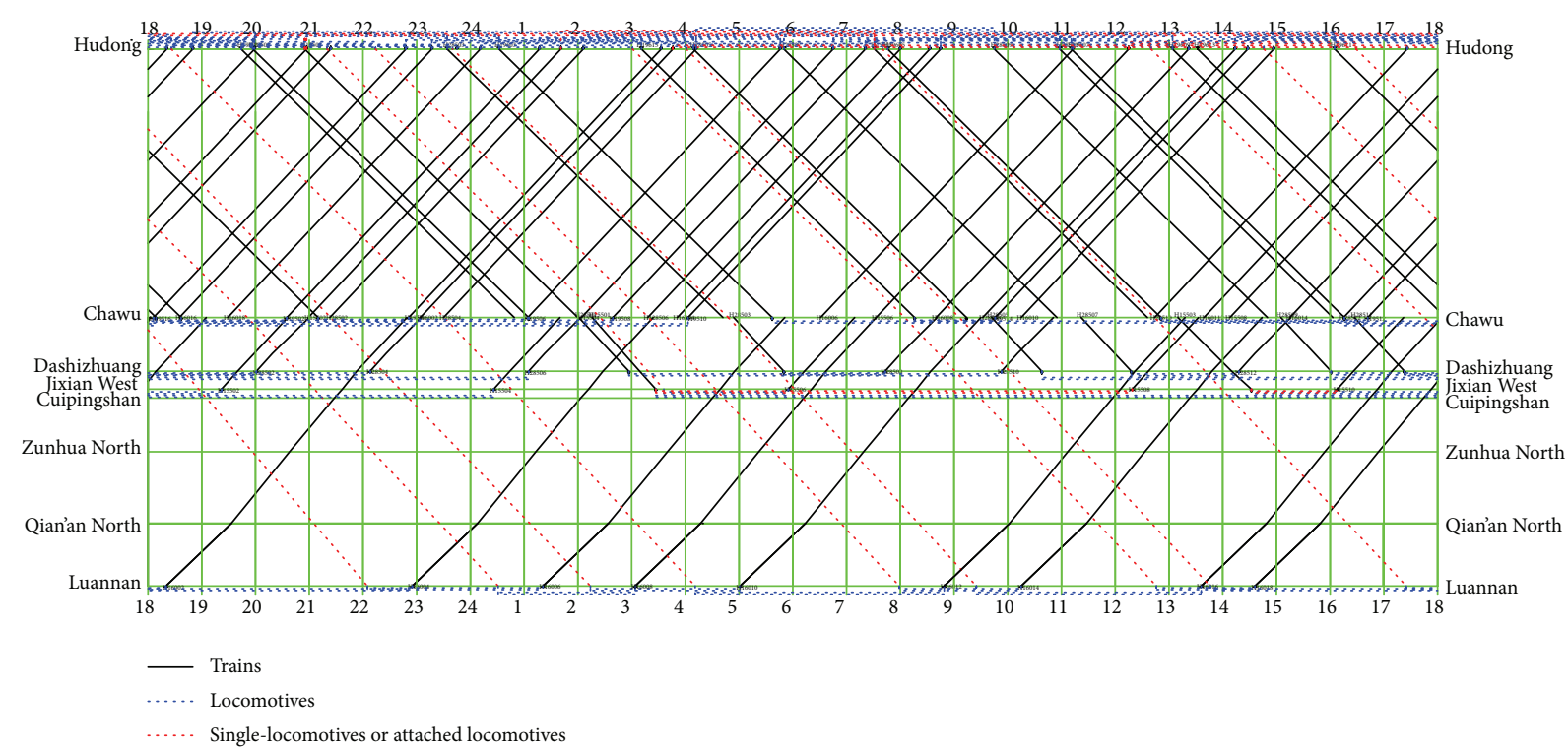

FIGURE 11: Locomotive working diagram of SS4 locomotives for $20 \mathrm{kt}$ combined trains.

TABLE 4: The daily number of locomotives on Da-qin Railway on December 10, 2014 [21].

\begin{tabular}{lccc}
\hline $\begin{array}{l}\text { Types of } \\
\text { locomotive }\end{array}$ & $\begin{array}{c}\text { Daily number of } \\
\text { locomotives }\end{array}$ & $\begin{array}{c}\text { Types of } \\
\text { locomotive }\end{array}$ & $\begin{array}{c}\text { Daily number of } \\
\text { locomotives }\end{array}$ \\
\hline HXD1 & 130 & SS4 & 109 \\
HXD2 & 92 & - & - \\
\hline
\end{tabular}

The locomotive connection scheme can be represented as a locomotive working diagram which is shown in Figure 11.

\subsubsection{Analysis of Result}

(1) Analyze the Number of Available Locomotives. The number of available locomotives (the total number of locomotives after deducting locomotives in maintenance and preparation) on Da-qin Railway on December 10, 2014 is shown in Table 4.

Table 4 indicates that the locomotive schedule obtained by using the model can save the number of HXD locomotives, $130+92-209=13$, and the number of SS4 locomotives, $109-30 \times 2=49$. Therefore, if only the minimum number of locomotives is considered, the optimization model of heavy haul locomotive schedule will be optimized.

(2) Analyze the Equilibrium of Locomotive Schedule. The equilibrium degree of locomotive schedule of HXD locomotives and SS4 locomotives is, respectively,

$$
\begin{aligned}
D_{\mathrm{HXD}} & =\frac{1}{328} \sum_{k=1}^{13} \sum_{i=1}^{328} \sum_{j=1}^{328}\left(c_{i, j}^{k} x_{i, j}^{k}-\frac{Z}{328}\right)^{2}=52379 \\
D_{\mathrm{SS} 4} & =\frac{1}{56} \sum_{k=1}^{13} \sum_{i=1}^{56} \sum_{j=1}^{56}\left(c_{i, j}^{k} x_{i, j}^{k}-\frac{Z}{56}\right)^{2}=74044 .
\end{aligned}
$$

The equilibrium degree of the locomotive schedule for HXD locomotives and SS4 locomotives is smaller than the equilibrium degree of that case, which shows that this locomotive schedule is more balanced. The equilibrium degree of SS4 locomotives is larger than the equilibrium degree of HXD locomotives, which shows that the schedule of HXD locomotives is more balanced than SS4 locomotives. The large equilibrium degree of SS4 locomotives may be due to the small detention time of locomotives at stations.

5.3. Research and Analysis of Locomotive Schedule Optimization for $30 \mathrm{kt}$ Combined Trains on Da-qin Railway. On the basis of the potential train diagram for $30 \mathrm{kt}$ combined trains, the practical and feasible locomotive connection scheme can be determined by using the optimization model.

In reference to the mentioned method, complete the data processing.

5.3.1. Result. The results are illustrated as follows.

The minimum waiting times of locomotives at stations are, respectively,

$$
\begin{aligned}
Z_{\mathrm{HXD}} & =\sum_{k=1}^{13} \sum_{i=1}^{406} \sum_{j=1}^{406} c_{i, j}^{k} x_{i, j}^{k}=44838(\mathrm{~min}), \\
Z_{\mathrm{SS} 4} & =\sum_{k=1}^{13} \sum_{i=1}^{52} \sum_{j=1}^{52} c_{i, j}^{k} x_{i, j}^{k}=10314(\mathrm{~min}) .
\end{aligned}
$$

The minimal technological times of locomotives at stations are, respectively,

$$
\begin{aligned}
T_{K}^{\mathrm{HXD}} & =203 \times 250+64 \times 220+65 \times 100+74 \times 50 \\
& =75030(\mathrm{~min}), \\
T_{K}^{\mathrm{SS} 4} & =26 \times 250+26 \times 50=7800(\mathrm{~min}) .
\end{aligned}
$$


TABLE 5: The average number of locomotives in Da-qin Railway in 2014.

\begin{tabular}{lccc}
\hline Types of locomotive & $\begin{array}{c}\text { The possessive quantity of } \\
\text { locomotives }\end{array}$ & $\begin{array}{c}\text { The locomotive number of } \\
\text { 20 kt combined trains }\end{array}$ & $\begin{array}{c}\text { The locomotive number of } \\
\text { 30 kt combined trains }\end{array}$ \\
\hline HXD & 251 & 209 & 251 \\
SS4 & 105 & 60 & 58 \\
\hline
\end{tabular}

The running times of locomotives are, respectively,

$$
\begin{aligned}
T_{t}^{\mathrm{HXD}} & =241572(\mathrm{~min}), \\
T_{t}^{\mathrm{SS} 4} & =23646(\mathrm{~min}) .
\end{aligned}
$$

According to that data, the minimum numbers of locomotives are, respectively,

$$
\begin{aligned}
M_{\mathrm{HXD}} & =\frac{T_{t}+T}{1440}=\frac{T_{t}+T_{K}+Z}{1440} \\
& =\frac{241572+75030+44838}{1440}=\frac{361440}{1440}=251, \\
M_{\mathrm{SS} 4} & =\frac{T_{t}+T}{1440}=\frac{T_{t}+T_{K}+Z}{1440} \\
& =\frac{23646+7800+10314}{1440}=\frac{41760}{1440}=29 .
\end{aligned}
$$
tively,

So, the coefficients of locomotive requirement are, respec-

$$
\begin{aligned}
K_{d}^{\mathrm{HXD}} & =\frac{M_{\mathrm{HXD}}}{n}=\frac{251}{59+3+20}=3.06, \\
K_{d}^{\mathrm{SS} 4} & =\frac{M_{\mathrm{SS} 4}}{n}=\frac{29 \times 2}{52 / 2}=2.23 .
\end{aligned}
$$

5.3.2. The Locomotive Connection Scheme and the Locomotive Schedule. According to the best connection matrix obtained, locomotive connection scheme for $30 \mathrm{kt}$ combined train on Da-qin Railway can be obtained. The locomotive connection scheme of SS4 locomotives is as follows:

$$
\begin{aligned}
& \mathrm{H} 16004 \longrightarrow \mathrm{H} 28503 \longrightarrow \mathrm{H} 28508 \longrightarrow \mathrm{H} 17215 \\
& \longrightarrow \mathrm{H} 17208 \longrightarrow \mathrm{H} 17203 \longrightarrow \mathrm{H} 17214 \\
& \longrightarrow \mathrm{H} 28507 \longrightarrow \mathrm{H} 28512 \longrightarrow \mathrm{H} 28501 \\
& \longrightarrow \mathrm{H} 28506 \longrightarrow \mathrm{H} 28515 \longrightarrow \mathrm{H} 28504 \\
& \longrightarrow \mathrm{H} 15505 \longrightarrow \mathrm{H} 15502 \longrightarrow \mathrm{H} 19605 \\
& \longrightarrow \mathrm{H} 19502 \longrightarrow \mathrm{H} 17209 \longrightarrow \mathrm{H} 17202 \\
& \longrightarrow \mathrm{H} 17211 \longrightarrow \mathrm{H} 17206 \longrightarrow \mathrm{H} 17213 \\
& \longrightarrow \mathrm{H} 17210 \longrightarrow \mathrm{H} 15503 \longrightarrow \mathrm{H} 15506 \\
& \longrightarrow \mathrm{H} 28505 \longrightarrow \mathrm{H} 28510 \longrightarrow \mathrm{H} 17201 \\
& \longrightarrow \mathrm{H} 17212 \longrightarrow \mathrm{H} 17205 \longrightarrow \mathrm{H} 17216 \\
& \longrightarrow \mathrm{H} 28509 \longrightarrow \mathrm{H} 28514 \longrightarrow \mathrm{H} 16003 \\
& \longrightarrow \mathrm{H} 16008 \longrightarrow \mathrm{H} 28511 \longrightarrow \mathrm{H} 28516
\end{aligned}
$$

$$
\begin{aligned}
& \longrightarrow \mathrm{H} 17207 \rightarrow \mathrm{H} 17204 \rightarrow \mathrm{H} 28513 \\
& \longrightarrow \mathrm{H} 28502 \rightarrow \mathrm{H} 16005 \rightarrow \mathrm{H} 16002 \\
\mathrm{H} 19601 & \longrightarrow \mathrm{H} 16007 \rightarrow \mathrm{H} 16004 ; \\
& \longrightarrow \mathrm{H} 16001 \rightarrow \mathrm{H} 15504 \longrightarrow \mathrm{H} 15504 \\
& \longrightarrow \mathrm{H} 19506 \rightarrow \mathrm{H} 19606 \rightarrow \mathrm{H} 19603 \\
&
\end{aligned}
$$

The locomotive connection scheme can be represented as a locomotive working diagram which is shown in Figure 12.

\subsubsection{Analysis of Result}

(1) Analyze the Number of Available Locomotives. The daily average number of available locomotives in 2014 can be treated as the daily number of locomotives which is shown in Table 5.

Analyzing the data in Table 5, it is obvious that the locomotive schedule just meets the needs of HXD locomotives and saves the number of SS4 locomotives: $105-29 \times 2=47$. Therefore, for the given train diagram for $30 \mathrm{kt}$ combined trains, all trains will be operated smoothly.

(2) Analyze the Equilibrium of Locomotive Schedule. The equilibrium degree of locomotive schedule of HXD locomotives and SS4 locomotives is, respectively,

$$
\begin{aligned}
D_{\mathrm{HXD}} & =\frac{1}{406} \sum_{k=1}^{13} \sum_{i=1}^{406} \sum_{j=1}^{406}\left(c_{i, j}^{k} x_{i, j}^{k}-\frac{Z}{406}\right)^{2}=40812, \\
D_{\mathrm{SS} 4} & =\frac{1}{52} \sum_{k=1}^{13} \sum_{i=1}^{52} \sum_{j=1}^{52}\left(c_{i, j}^{k} x_{i, j}^{k}-\frac{Z}{52}\right)^{2}=47201 .
\end{aligned}
$$

Compared to the optimal locomotive schedule of the current diagram, the equilibrium degree of the potential locomotive schedule is smaller. It shows that the potential locomotive schedule is more balanced. The equilibrium degree of SS4 locomotives is larger than the equilibrium degree of HXD locomotives, which shows that the schedule of HXD locomotives is more balanced than that of SS4 locomotives.

\section{Conclusions}

The rationality of locomotive schedule has a direct impact on the transportation efficiency and benefit. Therefore, it is 


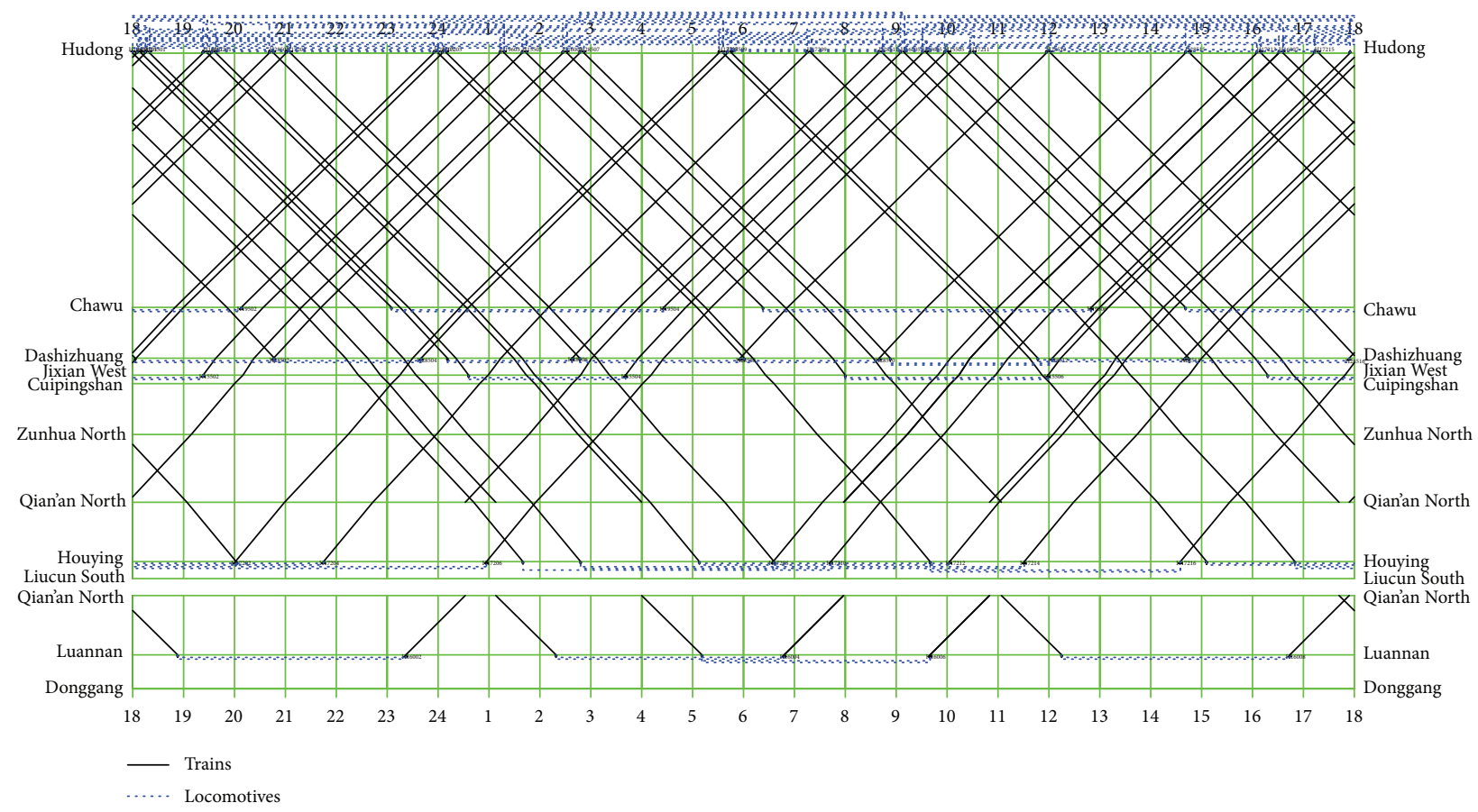

FIGURE 12: Locomotive working diagram of SS4 locomotives for $30 \mathrm{kt}$ combined trains.

necessary to study how to improve the locomotive scheduling efficiency.

The following conclusions can be drawn on the comparisons of the locomotive schedule for $30 \mathrm{kt}$ combined trains of the potential train diagram and the optimized locomotive schedule for $20 \mathrm{kt}$ combined trains of the current train diagram:

(1) For the given feasible train diagram for $30 \mathrm{kt}$ combined trains on Da-qin Railway, all trains will be operated smoothly. The HXD locomotives just meet the needs while the remaining number of SS4 locomotives is 44 . Therefore, in the actual transportation operations, it needs to strengthen monitoring and maintenance of HXD locomotives and for SS4 locomotives. It is an obvious effective way that increases the quantities of locomotives for operating trains to reduce the equilibrium degree of locomotive schedule.

(2) Increasing the minimal technological time of locomotives at stations can reduce the equilibrium degree of the locomotive schedule and make locomotive schedule more balanced.

(3) Strengthen reconnection between different locomotive types. At present, $15 \mathrm{kt}$ combined trains are hauled by two HXD locomotives. The hauling weight of one HXD locomotive is 10 kilotons, so there will be some waste of hauling weight. The hauling weight of one SS4 locomotive is 5 kilotons. Therefore, if the reconnection operation and synchronization control between HXD locomotives and SS4 locomotives can be realized by LOCOTROL technology, one $15 \mathrm{kt}$ combined train will be successfully hauled by one HXD locomotive and one SS4 locomotive, which will release the hauling weight and make the transportation tasks complete more smoothly.

\section{Conflict of Interests}

The authors declare that there is no conflict of interests regarding the publication of this paper.

\section{Acknowledgments}

The material in this paper is based on research supported by "The Fundamental Research Funds for the Central Universities" under Grant no. 2015JBM057, "Research on Assessment and Improvement Train Schedule for High Speed Railway Based on Multi-Resource Constraint," and China Railway Corporation under Grant no. 2014X001-B, "Study on Transportation Scheduling for $30 \mathrm{kt}$ Combined Train in Da-qin Railway." The real data in this paper is based on research supported by Taiyuan Railway Administration. We would like to extend my sincere gratitude to Zhitong Huang and Peiheng Li for their careful review.

\section{References}

[1] X. Wu, "Study on traffic organization system of Da-qin Railway," Chinese Railway, vol. 6, pp. 11-15, 2009.

[2] National Bureau of Statistics of the People's Republic of China, China Statistical Yearbook, China Statistics Press, 2006-2015.

[3] Z. H. Cheng, F. X. Li, S. Wu, and P. Gao, "Application of reliability centered maintenance in railway locomotive-a case 
study," in Proceedings of the 1st International Conference on Maintenance Engineering, pp. 269-275, July 2006.

[4] F. Y. Zheng and Q. C. Wei, "Heavy-axle load mechanical effects on railway tracks," in Proceedings of the 2nd International Conference on Railway Engineering: New Technologies of Railway Engineering (ICRE '12), pp. 233-236, Beijing, China, July 2012.

[5] W. H. Chang, Research on the Mechanical Properties of 30 t Axle Heavy Haul Railway Track Structure, Beijing Jiaotong University, 2009.

[6] X. Mu, C. L. Yang, and M. Li, "Enlightenment of foreign railway heavy haul transport to the development of China's railway freight transport," Railway Economics Research, vol. 1, 2013.

[7] T. Raviv and M. Kaspi, "The locomotive fleet fueling problem," Operations Research Letters, vol. 40, no. 1, pp. 39-45, 2012.

[8] V. P. Kumar and M. Bierlaire, "Optimizing fueling decisions for locomotives in railroad networks," Transportation Science, vol. 49, no. 1, pp. 149-159, 2015.

[9] B. Ji, X. M. Diao, and S. X. Li, "Study on intercommunication between locomotives for heavy haul train on Da-qin line," Railway Locomotive \& Car, vol. 30, pp. 12-14, 2010.

[10] D. Ruppert, G. Hull, B. Green, R. Golden, G. Binns, and M. Latino, "Root cause analysis increases locomotive reliability at AMTRAK," in Proceedings of the ASME/IEEE Joint Rail Conference and the ASME Internal Combustion Engine Division Spring Technical Conference, pp. 305-310, Pueblo, Colo, USA, March 2007.

[11] C.-C. Kuo and G. M. Nicholls, "A mathematical modeling approach to improving locomotive utilization at a freight railroad," Omega, vol. 35, no. 5, pp. 472-485, 2007.

[12] M. Aronsson, P. Kreuger, and J. Gjerdrum, "An efficient MIP model for locomotive routing and scheduling," in Proceedings of the 12th International Conference on Computer System Design and Operation in Railways and Other Transit Systems, vol. 114, pp. 963-973, Beijing, China, September 2010.

[13] B. Vaidyanathan, R. K. Ahuja, and J. B. Orlin, “The locomotive routing problem," Transportation Science, vol. 42, no. 4, pp. 492507,2008 .

[14] K. Ghoseiri and S. F. Ghannadpour, "A hybrid genetic algorithm for multi-depot homogenous locomotive assignment with time windows," Applied Soft Computing Journal, vol. 10, no. 1, pp. 5365, 2010.

[15] S. Kasalica, D. Mandić, and V. Vukadinović, "Locomotive assignment optimization including train delays," PROMETTrafficeTransportation, vol. 25, no. 5, pp. 421-429, 2013.

[16] S. Rouillon, G. Desaulniers, and F. Soumis, "An extended branch-and-bound method for locomotive assignment," Transportation Research Part B: Methodological, vol. 40, no. 5, pp. 404-423, 2006.

[17] D. Teichmann, M. Dorda, K. Golc, and H. Bínová, "Locomotive assignment problem with heterogeneous vehicle fleet and hiring external locomotives," Mathematical Problems in Engineering, vol. 2015, Article ID 583909, 7 pages, 2015.

[18] C. B. Li, C. Ning, Q. Q. Guo, and J. Cheng, "An improved ant colony algorithm for making locomotive working diagram," in Proceedings of the 2nd International Conference of Modelling and Simulation, pp. 63-68, Manchester, UK, 2009.

[19] F. S. Zhu, C. M. Gao, J. P. Zhang, and B. Ji, "Optimizing plan discussion on the Da-qin railway heavy-loaded trains locomotive routing," Railway Locomotive \& Car, vol. 29, pp. 4$10,2001$.
[20] H. Yang, Railway Transport Organization, China Railway Publishing House, Beijing, China, 3rd edition, 2006.

[21] TaiYuan RailWay Administration, Technical Information of Train Schedule, TaiYuan RailWay Administration, 2012.

[22] C. J. Guo and D. Y. Lei, "Model of wagons' placing-in and takingout problem in a railway station and its Heuristic algorithm," Mathematical Problems in Engineering, vol. 2014, Article ID 493809, 8 pages, 2014. 


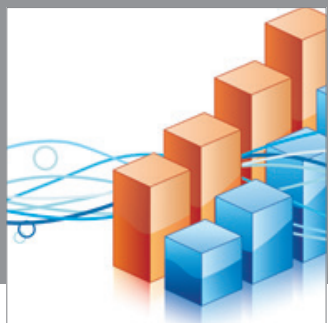

Advances in

Operations Research

mansans

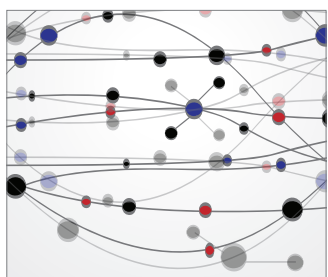

The Scientific World Journal
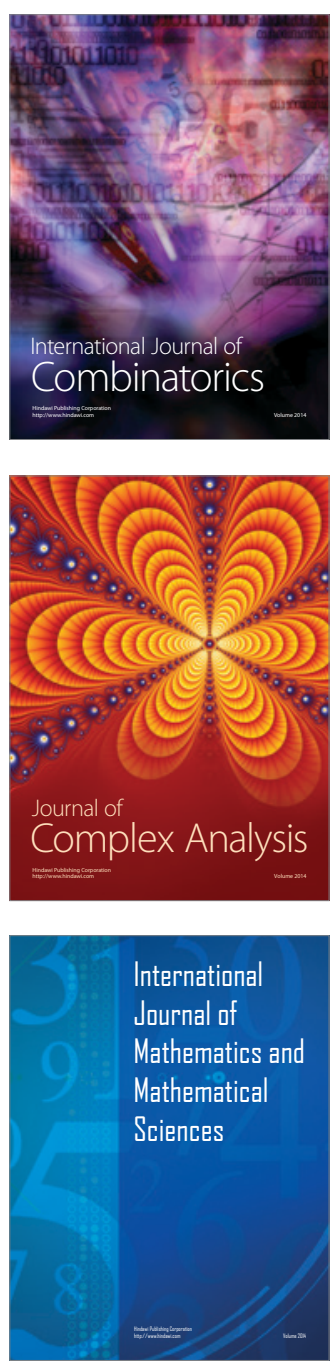
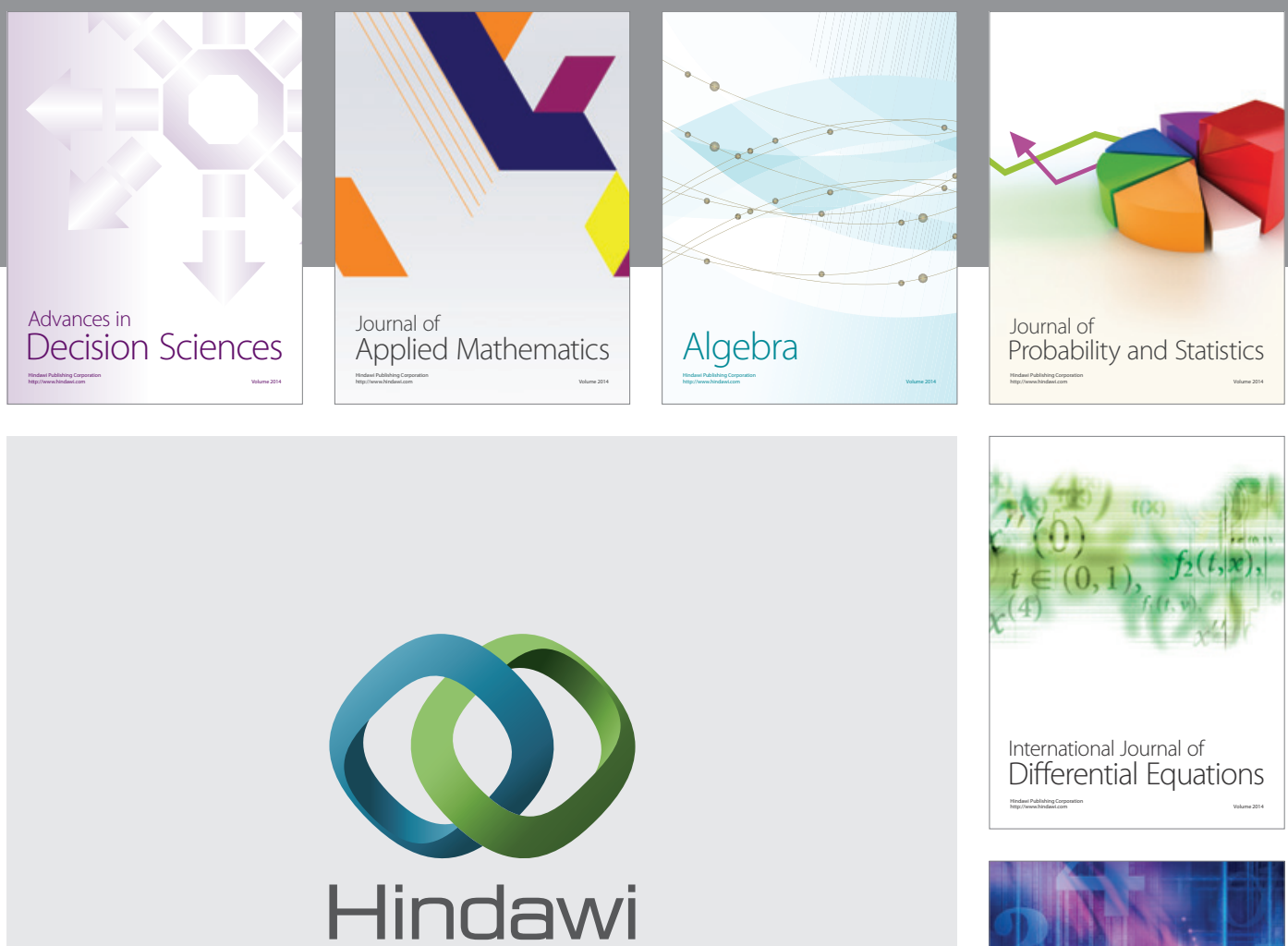

Submit your manuscripts at http://www.hindawi.com
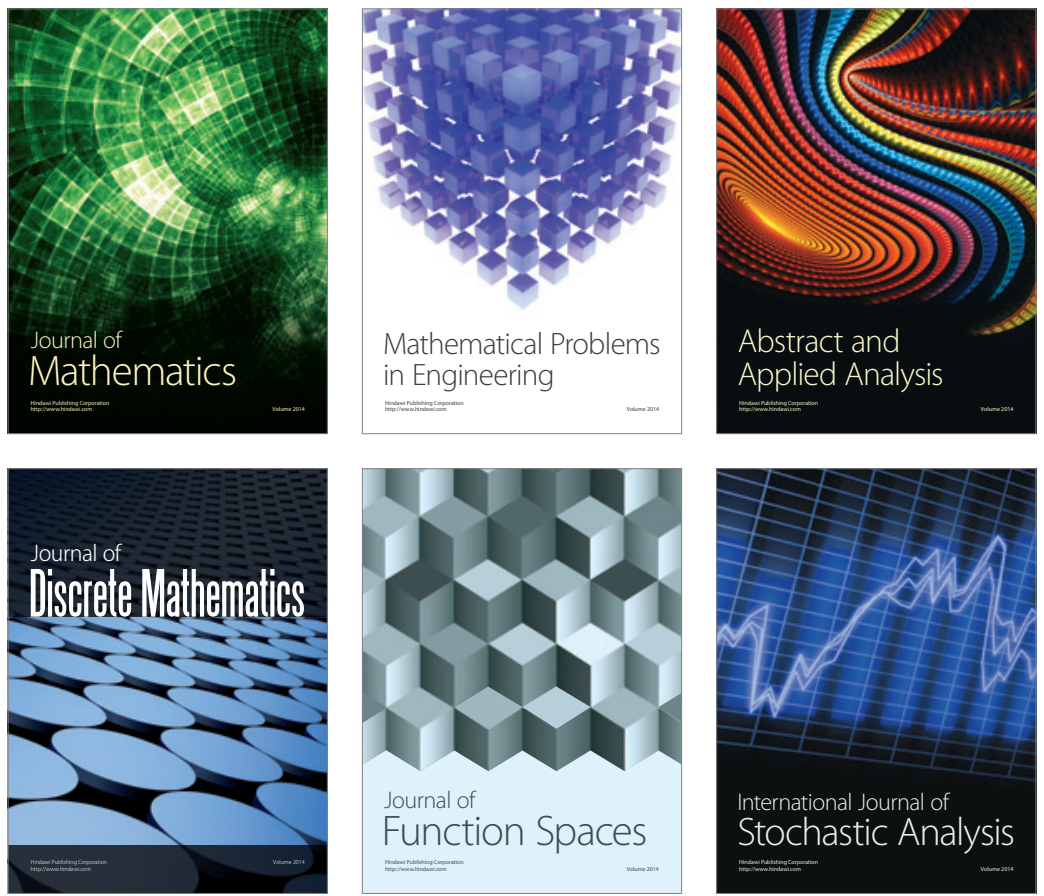

Journal of

Function Spaces

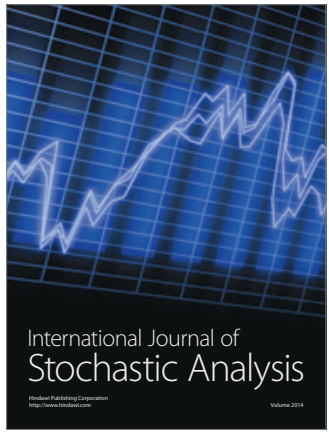

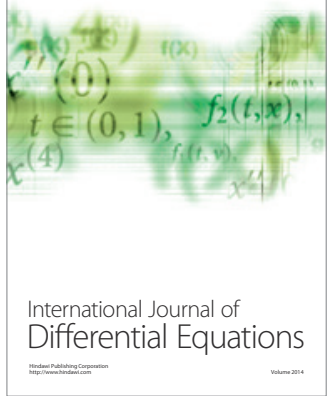
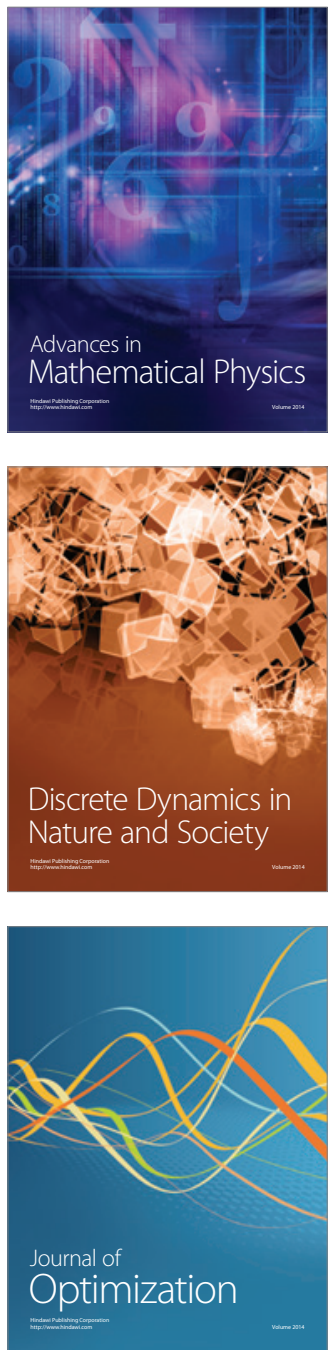